\title{
Immigration, diversity and trust: the competing and intersecting role of English language ability in the community
}

DOI:

10.1080/01419870.2021.2021263

\section{Document Version}

Final published version

Link to publication record in Manchester Research Explorer

Citation for published version (APA):

Lymperopoulou, K., Winiowski, A., \& Laurence, J. (2022). Immigration, diversity and trust: the competing and intersecting role of English language ability in the community. Ethnic and racial studies, 45(16), 189-215. https://doi.org/10.1080/01419870.2021.2021263

\section{Published in:}

Ethnic and racial studies

\section{Citing this paper}

Please note that where the full-text provided on Manchester Research Explorer is the Author Accepted Manuscript or Proof version this may differ from the final Published version. If citing, it is advised that you check and use the publisher's definitive version.

\section{General rights}

Copyright and moral rights for the publications made accessible in the Research Explorer are retained by the authors and/or other copyright owners and it is a condition of accessing publications that users recognise and abide by the legal requirements associated with these rights.

\section{Takedown policy}

If you believe that this document breaches copyright please refer to the University of Manchester's Takedown Procedures [http://man.ac.uk/04Y6Bo] or contact uml.scholarlycommunications@manchester.ac.uk providing relevant details, so we can investigate your claim.

\section{OPEN ACCESS}




\section{Immigration, diversity and trust: the competing and intersecting role of English language ability in the community}

\section{Kitty Lymperopoulou, Arkadiusz Wiśniowski \& James Laurence}

To cite this article: Kitty Lymperopoulou, Arkadiusz Wiśniowski \& James Laurence (2022) Immigration, diversity and trust: the competing and intersecting role of English language ability in the community, Ethnic and Racial Studies, 45:16, 189-215, DOI: 10.1080/01419870.2021.2021263

To link to this article: https://doi.org/10.1080/01419870.2021.2021263

\section{○}

(C) 2022 The Author(s). Published by Informa

UK Limited, trading as Taylor \& Francis Group

\section{央 Published online: 21 Jan 2022.}

Submit your article to this journal $\sqsubset$

Q View related articles $\sqsubset$

View Crossmark data $\nearrow$ 


\title{
Immigration, diversity and trust: the competing and intersecting role of English language ability in the community
}

\author{
Kitty Lymperopoulou (DiD ${ }^{a}$, Arkadiusz Wiśniowski (iD ${ }^{b}$ and James \\ Laurence (iD) ${ }^{b, c}$ \\ ${ }^{a}$ Manchester Metropolitan University, Manchester, UK; ${ }^{b}$ University of Manchester, \\ Manchester, UK; ' Economic and Social Research Institute, Dublin, Ireland
}

\begin{abstract}
A growing number of studies have shown adverse effects of ethnic diversity on social cohesion routed in ethnic categorical differences, competition and racial threat. We build on previous research by examining the hypothesis that cultural (language) differentiation leads to lower intra-neighbourhood trust through feelings of anomie. Our results, based on data from the 2009-2011 UK Citizenship survey and a multilevel modelling framework, do not offer support for the proposition that diversity lowers trust through linguistic diversity and poor communication. In line with other studies, we find a negative association between ethnic diversity and trust and show that for the white group, this relationship does not depend on migrants' levels of fluency in the majority language. In contrast, in neighbourhoods where migrants cannot speak English well, increases in ethnic diversity are associated with higher levels of neighbour trust among the non-white group.
\end{abstract}

ARTICLE HISTORY Received 14 December 2020; Accepted 2 December 2021

KEYWORDS immigration; ethnic diversity; linguistic diversity; language proficiency; trust; cohesion

\section{Introduction}

Against the backdrop of increasing levels of immigration in the UK, there has been a lot of interest in the social consequences of increasing levels of ethnic diversity and the ways it is impacting on social relations and trust in local communities. Social cohesion became a policy focus during the New Labour years, following the 2001 riots in northern England which resulted in a series of "community cohesion" initiatives and policies to enable "different groups of people get on well together" (Commission on Integration and Cohesion 2007, 38). There was also increased emphasis on the promotion 
of the learning of a "common" language and values among new immigrants (Cheong et al. 2007) which continued through the Conservative and Coalition government years. The Casey Review (Casey 2016) and the Integrated Communities Strategy White Paper (HM Government 2018) highlighted ethnic diversification as a continued challenge for social cohesion in British society, seen to be undermined by high levels of immigration and the residential segregation of ethnic minorities. Public disquiet about immigration is thought to have been instrumental in the vote for "Brexit" in the 2016 EU membership referendum (Ford and Goodwin 2014) which revealed persistent societal divisions over views on immigration among the British public (Ford and Lymperopoulou 2017).

Academic interest on the effect of ethnic diversity on social cohesion grew rapidly following Robert Putnam's (2007) influential study which offered support to what came to be known as the constrict hypothesis: diversity reduces both in-group and out-group solidarity. Despite the mixed support for Putnam's (2007) findings, particularly outside the US, an increasing number of studies have shown a negative effect of ethnic diversity on neighbourhood trust and cohesion (Laurence 2017; van der Meer and Tolsma 2014). At the same time, previous research has indicated that it is not diversity in itself which undermines solidarity and trust in society, but the way in which this diversity is organized (Levrau and Loobuyck 2013). In the UK, ethnic minority groups are overwhelmingly concentrated in socio-economically deprived areas, and several studies have shown that after controlling for area deprivation, ethnic diversity has little or no effect on social cohesion (Letki 2008; Laurence 2011; Becares et al. 2011; Sturgis et al. 2011; Sturgis et al. 2014). The effect of ethnic diversity on trust within neighbourhoods has also been shown to depend on levels of residential segregation, with ethnic diversity impacting negatively on neighbour trust only in more segregated areas (Laurence 2017). By and large, the conditions under which ethnically diverse environments affect social cohesion remain under-researched, and there is limited empirical evidence about how they relate to theoretical propositions about the mechanisms through which ethnic diversity affects trust (Tolsma and van der Meer 2017).

The bulk of studies examining the effects of ethnic diversity on social cohesion have drawn on racial threat (Blalock 1967) and contact theories (Allport 1954) which offer competing explanations about the ways increases in ethnic diversity affect levels of social cohesion. These studies have tended to examine the association between diversity and social cohesion in terms of cognitive biases related to ethno-categorical differences (Schaeffer 2013) using measures such as the size of the ethnic minority population, fractionalization and segregation indices (van der Meer and Tolsma 2014), which ignore any cultural or economic distances between ethnic categories (Schaeffer 2013). We contend this is an important limitation given long-standing evidence that 
attitudes towards immigration and ethnic diversity are selective and depend on migrants' skills and take up of language, common values, behaviours or customs in the receiving country (Ford and Lymperopoulou 2017). Cultural differentiation, and particularly linguistic diversity, is expected to lower trust by creating anxieties about a lack of knowledge about shared social norms and values. Poor communication, as a result of inability to speak the majority language, can inhibit social contact instigating feelings of anomie and distrust (van der Meer and Tolsma 2014; Tolsma and van der Meer 2017). In the UK, there has been a lot of political attention on the negative effects of ethnic diversity that arise from cultural differentiation, and particularly on the links between poor English language ability and low interethnic contact, with low social cohesion attributed to the recency of immigration (Casey 2016). Yet, the assertion that migrants' poor language ability undermines social cohesion does not seem to be borne out in the existing evidence. To our knowledge, there has been no previous attempt in the UK to examine how the composition of ethnic diversity in terms of language fluency in the majority language is associated with trust.

Another potential issue with current studies is that many have focused on the relationship between the diversity of an area and the reported trust among all residents; both majority- and minority-group residents. This stems from the assumption that all residents of an area are likely to experience weaker cohesion (Putnam 2000). However, when studies have disaggregated the experiences of majority-/minority groups, much of the declining cohesion observed in diverse communities occurs among the majority (often white) group, while minority groups tend to report more mixed findings, with some demonstrating a negative effect but others showing little substantive difference in trust across levels of community diversity (Leigh 2006; Gundelach and Freitag 2014; Schmid, Ramiah, and Hewstone 2014; Abascal and Baldassarri 2015). Accordingly, examining how diversity affects cohesion needs to consider how these processes may differ for majority-/minority groups.

In this paper, we present an analysis on the effect of ethnic diversity on trust in England using data from the 2009-2011 Citizenship Survey matched to a range of Census and administrative data. We estimate multilevel models of trust which allow us to examine conditions relating to the composition of the migrant population, in particular, English language proficiency, under which we can expect ethnic diversity to affect levels of trust. Our results do not offer support for the proposition that diversity lowers trust through cultural differentiation. In line with other studies, we find a negative association between ethnic diversity and trust for the white group, and to a lesser extent for the non-white group. However, we also find that for the non-white group this relationship depends on the ability of migrants to speak the majority language. Increases in ethnic diversity levels in neighbourhoods with higher concentrations of migrants with poor 
English language fluency are associated with increases in levels of trust for the non-white group. In contrast, among the majority white group, increases in neighbourhood ethnic diversity are associated with lower neighbour trust irrespective of the ability of migrants to speak the majority language.

\section{Ethnic diversity, racial threat and cultural differentiation}

Explanations of the mechanisms through which immigration impacts negatively on trust draw on the "racial threat" hypothesis which postulates that as a minority-group in an area increases, this fuels prejudice and hostility as majority-group members feel threatened they will lose their power and privileges (Blalock 1967). Racial threat, prejudice and hostility have been shown to be interlinked with economic conditions and arise from either blaming a subordinate group for economic hardship (scapegoating), or from competition for scarce resources (Quillian 1995, 590). Racial threat is intensified when majority groups perceive their economic circumstances as precarious and fear they will lose their economic advantages, for instance, in terms of employment and housing, over the subordinate group (Quillian 1995).

Empirical support for the racial threat hypothesis has been somewhat mixed. While many studies, particularly in the US, find a negative association between ethnic diversity and cohesion, other studies find a negligible effect of diversity on cohesion, or even, a positive effect (van der Meer and Tolsma 2014). Sturgis et al. (2011) tested the racial threat hypothesis in the UK and concluded "if diversity does reduce trust in one's neighbours, it would not appear to be a result of competition, real or imagined, between different ethnic groups for scarce local resources"(79). The lack of consensus in empirical findings may relate to differences in the ways ethnic heterogeneity and social cohesion have been operationalized in studies, the use of individuallevel versus aggregate data, and the geographic scales examined (van der Meer and Tolsma 2014; Abascal and Baldassarri 2015). For example, there is more consistent support for the constrict claim for aspects of intra-neighbourhood social cohesion such as trust towards neighbours than broader aspects of cohesion (van der Meer and Tolsma 2014). The negative effect of ethnic outgroup size on non-intra-neighbourhood cohesion measures generally holds for large geographic areas, such as districts, counties or countries, but when this effect is examined at the local neighbourhood level it is often found to be weaker or even positive (see Kaufmann and Harris 2015; van der Meer and Tolsma 2014; Tolsma and van der Meer 2017). Another explanation for the divergent research findings is the failure to account for confounders of the association between ethnic diversity and trust. Abascal and Baldassarri (2015) showed that residential stability and economic well-being are the strongest predictors of trust. They also showed that low levels of trust in ethnically diverse communities conceals the aversity of white groups to diversity 
and is an "artifact of nonwhites' lower levels of trust combined with their overrepresentation in diverse communities" (723). In the UK, Becares et al. (2011) and Sturgis et al. (2014) showed that neighbourhood ethnic diversity is positively related to social cohesion after the level of economic deprivation is taken into account. These results seem to offer support for the "contact" hypothesis developed by Allport (1954) which suggests that when ethnic diversity increases, the likelihood of meaningful interactions and friendships between ethnic groups increase, preventing negative perceptions, misinformation, and rumours regarding other ethnic groups. As highlighted by Laurence and Heath (2008, 14-15), although suggesting different effects of increased diversity on cohesion, the "contact hypothesis" and "threat hypothesis" may be part of the same process. Competition following the arrival of migrants can be expected to diminish over time as immigrants and established communities adapt to each other, and with increased social interaction. Second-generation immigrants may also find it easier to mix with people from different backgrounds and to establish interethnic ties and greater cohesion, partly as a result of lower social distance and language adaptation (Laurence and Heath 2008).

Another mechanism through which higher ethnic and linguistic diversity may lead to lower trust is through feelings of anomie - individual anxiety about the existence of shared societal norms and moral values - leading to social disorganization of the environment (van der Meer and Tolsma 2014, 463). The anomie mechanism "starts from a true context effect of ethnic heterogeneity itself" which arises from linguistic diversity (Tolsma and van der Meer 2017, 639). A lack of knowledge about shared social norms and values, and shared participation and meaning, coupled with barriers to communication, will stimulate feelings of exclusion and aimlessness preventing contact and familiarity with neighbours (van der Meer and Tolsma 2014; Tolsma and van der Meer 2017). A common language is considered to be a precondition for cohesion and coordination by enabling a common set of practices and schemes necessary to communicate about the existence of shared preferences (Schaeffer 2013), aiding the development of democratic solidarity and trust (Levrau and Loobuyck 2013). Prejudices and suspicion towards immigrants and ethnic minorities may therefore arise from problems in the exchange of meaning and coordination problems arising from linguistic diversity (Schaeffer 2013). Language is also recognized as a key marker of social identity and group belongingness (Larsen et al. 2009). Coming into contact with others unable to speak the national-language may thus act as a prime (alongside visual cues, such as dress or religious symbols), heightening the saliency of group-membership (and perceived difference), as well as linking the encounter to political narratives regarding immigration that trigger perceived threat (Druckman et al. 2010; Hopkins, Tran, and Williamson 2014). Language barriers might also affect the quality of contact experienced, 
reducing opportunities for positive contact and increasing the likelihood that contact will be negative, and harmful to intergroup attitudes (Hopkins, Tran, and Williamson 2014; Laurence and Kim 2021). Studies indeed demonstrate that exposure to foreign languages can induce anxiety about ethnic differences and immigration (Hopkins, Tran, and Williamson 2014; Enos 2014; Laurence and Kim 2021).

Empirical evidence on the effect of language on social cohesion is limited, and what evidence exists is somewhat mixed, with some studies showing that linguistic diversity lowers trust, and that language proficiency in the majority language explains the negative link between ethnic diversity, trust and cohesion, while others find no effect of the ability to speak the majority language on social cohesion (Leigh 2006; Lancee and Dronkers 2011; Koopmans and Schaeffer 2015). To date, the effect of neighbourhood linguistic diversity and majority language fluency on cohesion have been overlooked in UK studies. Our analysis makes an important contribution to the existing literature in this respect. We argue that including a measure of ability to speak the majority language alongside diversity is important, because a key moderator of the relationship between ethnic diversity and trust is the level of meaningful social contact between groups (Sturgis et al. 2014). A common language is expected to facilitate contact and meaningful relationships to be formed and enable communication, to help resolve stereotypes and reduce prejudice between ethnic groups, and hence increase cohesion (Schaeffer 2013). Seen in this way, poor language fluency in the majority language among immigrants would be expected to make interethnic group communication more difficult, lead to mistrust and create anxieties that heighten racial conflict (Allport 1954). In other words, potentially, the extent to which groups in an area speak the same language (and speak it well) may moderate how far levels of ethnic diversity negatively impact cohesion.

\section{Majority-/Minority-group differences}

In theory, ethnic diversity is posited to undermine cohesion among all residents (Putnam 2007). However, there are several reasons to think the diversity/cohesion relationship may be more complex for ethnic minority-group residents, and current research indeed demonstrates more mixed support for the idea that ethnically diverse communities also harm cohesion among minority groups (Gundelach and Freitag 2014; Schmid, Ramiah, and Hewstone 2014; Abascal and Baldassarri 2015).

The first reason is a statistical one, linked to the oft-used measures of ethnic fractionalization applied to capture ethnic diversity in the literature. In theory, such measures pick up how ethnically fractionalized an environment is. However, in practice, such measures are extremely highly correlated with measures of percent ethnic minority in a community and are largely 
indistinguishable from one another (Schaeffer 2013). This may have implications for how we expect ethnic diversity to impact trust among ethnic minorities. If minorities in more diverse communities are more likely to be living among in-group members, then potentially, any negative impact of diversity emerging from majority-group distrust of minorities may be offset by positive effects of diversity emerging from cohabitation with more co-ethnics (Schaeffer 2013; Gundelach and Freitag 2014; Abascal and Baldassarri 2015).

The second reason the relationship may be more complex relates to the theories drawn on to explain weaker cohesion in diverse communities. On one hand, processes of perceived threat, where exposure to out-groups triggers perceived threats to social/economic resources, likely matter less for subordinate, ethnic minority groups than for the majority-group, given their relative status in society (Gundelach and Freitag 2014). Studies on the integration paradox (Ziller 2017; de Vroome, Martinovic, and Verkuyten 2014) have shown that economically integrated ethnic minority groups have higher perceptions of discrimination and experiences of unequal treatment as a result of more frequent exposure to the majority group, which affects negatively their attitudes towards other groups and trust. Viewed in this light, ethnic minority groups living in areas with high levels of ethnic minority concentration may develop higher levels of trust because of lower instances of negative socialization experiences and discrimination resulting from contact with majority groups (Ziller and Spörlein 2020).

However, on the other hand, ethnic minorities living among greater proportions of other ethnic minority out-groups could still experience perceived threats, for example when more-established migrant communities experience increases in newer-arriving minority groups in an area (Huijts, Kraaykamp, and Scheepers 2014). At the same time, ethnic minority individuals may still experience greater anomie at higher levels of ethnic/linguistic diversity, despite potentially living among more co-ethnics, given minority groups may still feel a lack of shared norms and values with other ethnic minority groups who are also present in more diverse communities (van der Meer and Tolsma 2014). In sum, from the current theoretical framework, it remains unclear exactly how community diversity will be associated with minority group cohesion.

This complexity in how we expect minority-group members to react to diverse communities could also extend to the (outlined) potential role of majority-group language proficiency in an area to moderate the effects of diversity on cohesion. As among the majority-group, lower majority language proficiency in a community may similarly act as a barrier to inter-minoritygroup interaction and communication. Thus, minorities living in diverse areas where proficiency is low may similarly perceive shared norms and values to be weaker, experience greater anxiety, and thus report comparatively lower trust than minorities in equally diverse areas where proficiency 
is higher. However, another possibility is that levels of language proficiency in a community could positively moderate how ethnic diversity affects trust for minority-group members. As we will discuss below, areas with a stronger immigrant identity (for example, where people are less likely to speak the majority-group language) may be more conducive to the formation of trust, than a shared language.

Several studies have identified that intergroup relations ultimately depend on the socio-cultural and historical community features of communities and the presence, or absence, of power and status hierarchies and social and economic inequalities between ethnic groups (Robinson and Reeve 2006; Robinson 2010; Zetter et al. 2006; Abascal and Baldassarri 2015). Recent empirical research through the lens of "superdiversity" has helped develop an understanding about the ways intergroup contact and trust are established and negotiated in diverse communities (Bynner 2019). A key feature of superdiverse communities is a multiplicity of characteristics of immigration in terms of countries of origin, ethnicities, language, religious affiliations, immigration and social statuses which interact in complex ways with the characteristics of local communities (Vertovec 2007), and the co-existence of "established" and "new" immigrant groups (Pemberton and Phillimore 2018). The diverse characteristics of "new" immigration have produced "new hierarchical social positions, statuses or stratifications", ... "new patterns of inequality and prejudice", and ... "new experiences of space and 'contact" (Vertovec 2019, 126). Within the superdiversity conceptual framework the role of a common language may therefore not be the "glue" that helps to hold a society together. Instead, shared history and experience of immigration may help build intergroup social connections and friendships to establish trust (Wessendorf 2014). This proposition seems to be supported by the findings presented in this study.

\section{Data and methods}

We examine the relationship between trust and ethnic and linguistic diversity in England using data from the Secure Access version of the 2009-2010 and 2010-2011 Citizenship Survey (Department for Communities and Local Government and Ipsos MORI 2012a, 2012b), matched to Middle Layer Super Output Area (MSOA) variables from the 2011 Census (ONS 2020), Communities and Local Government and the Office for National Statistics (ONS). We estimate models which include a range of individual and neighbourhood level variables that have been shown to be associated with intra-neighbourhood trust (Lymperopoulou and Wiśniowski 2019).

The Citizenship Survey is based on a nationally representative sample of around 10,000 individuals aged sixteen and above, and a minority ethnic boost sample of around 5,000 individuals in each year. The survey was 
conducted in multiple languages by bilingual interviewers or interpreters who carried a screening card and survey materials translated in eleven languages other than English to identify the language needs of households where English was not spoken well or not spoken at all. The languages included Arabic, Bengali, Cantonese, Gujarati, Hindi, Polish, Punjabi (Gurmukhi script), Punjabi (Urdu script), Somali and Urdu (for more details on the survey methodology see DCLG 2011).

\section{Measures}

In line with previous studies (Sturgis and Smith 2010), we use a measure of particularized trust from the Citizenship Survey which asks survey respondents how many of the people in their neighbourhood can be trusted. Our measure captures respondents in the Citizenship Survey who stated many of the people in their neighbourhood can be trusted (versus some, a few, or none, can be trusted).

The models control for individual respondent characteristics, such as age, gender marital status and the presence of children, income, socio-economic class, ethnicity, religion, country of birth, whether English was the main language spoken at home and the length of time the respondent had lived in the neighbourhood (see Table 1).

We used Middle Layer Super Output Areas (MSOA) to define neighbourhoods which are areas that have a mean population of around 7,500 people.

\section{Ethnic diversity}

The ethnic diversity of each MSOA was measured using Simpson's (1949) diversity index based on a thirteen ethnic group classification from the 2011 Census. The ethnic diversity index captures the probability that any two randomly selected individuals within a particular neighbourhood will be members of different ethnic groups.

\section{English language ability}

It has only been possible to examine the characteristics of neighbourhood ethnic diversity in relation to migrants' English language proficiency following the release of the 2011 Census which asked for the first time about main

Table 1. Sample sizes.

\begin{tabular}{lrrr}
\hline & Groups & White & Non-White \\
\hline Local authority & 319 & 318 & 259 \\
MSOA & 3,134 & 2,600 & 1,834 \\
Individuals & 24,813 & 13,032 & 11,781 \\
\hline
\end{tabular}

Note: There are 6792 MSOAs and 326 Local Authorities in England. Source: Citizenship Survey, pooled 2009/10-2010/11 (Secure Access). 
language other than English and proficiency in speaking English. Following Schaeffer (2013), to test whether the negative effect of ethnic diversity can be explained by communication and co-ordination problems we examine migrants' majority language skills measured by the proportion of people who cannot speak English well. The 2011 Census asked those who reported their main language as other than English to also state how well they can speak the English language. We grouped together those who stated "Not at all" and "Not well" to measure levels of (poor) English language ability.

\section{Co-ethnic and co-religious density}

Both of these variables are derived from the 2011 Census and capture the percentage of population belonging to respondents' ethnic group and percentage of population in the same religion (see Table 2 for the ethnic and religious categories used in the analysis).

\section{Deprivation levels}

We use the English indices of deprivation 2015 produced by the Department of Communities and Local Government (CLG) to measure income and crime deprivation in each MSOA. The MSOA income and crime domain scores were aggregated from LSOA IMD scores (see Smith et al. (2015) for details).

\section{Families and older age population}

We include measures capturing the proportion of the older age population (aged sixty-five plus) and the proportion of families with children. Perceptions of cohesion and tolerance towards new groups will typically vary by age and marital status, with younger people and those in families generally being more likely to be accepting of new immigrants than older people and single people (Sturgis et al. 2014).

\section{Rural}

We use the 2011 rural urban classification (ONS 2013) to identify rural MSOAs. Urban neighbourhoods have been consistently shown to exhibit lower cohesion and trust compared to rural areas (Laurence and Bentley 2017).

\section{Statistical analysis}

The analytical strategy involved estimating three-level logistic models of trust to take account of the clustered nature of the data and investigate sources of variation within and across clusters. As outlined, the processes linking ethnic diversity and majority-language proficiency in a community to local cohesion may differ for majority- and minority-group members. 
Table 2. Descriptive statistics of the data used in estimation.

\begin{tabular}{|c|c|c|c|c|}
\hline \multirow[b]{2}{*}{ Variable } & \multicolumn{2}{|c|}{ White } & \multicolumn{2}{|c|}{ Non-White } \\
\hline & Mean & SD & Mean & SD \\
\hline Trust (binary: trusts most of people in neighbourhood) & 0.53 & 0.5 & 0.25 & 0.43 \\
\hline \multicolumn{5}{|l|}{ Trusting (categories) } \\
\hline many of the people in your neighbourhood & 0.53 & 0.5 & 0.25 & 0.43 \\
\hline some can be trusted, & 0.33 & 0.47 & 0.43 & 0.5 \\
\hline a few can be trusted, & 0.13 & 0.33 & 0.27 & 0.44 \\
\hline or that none of the people in your neighbourhood & 0.02 & 0.14 & 0.05 & 0.21 \\
\hline \multicolumn{5}{|l|}{ Individual-level variables } \\
\hline Female (proportion) & 0.54 & 0.5 & 0.51 & 0.5 \\
\hline Age & 48.1 & 16.8 & 38 & 13.9 \\
\hline \multicolumn{5}{|l|}{ Respondent income (quintiles calculated using mid-ranges; proportions) } \\
\hline 1st (ref) & 0.18 & 0.38 & 0.31 & 0.46 \\
\hline 2nd & 0.18 & 0.39 & 0.17 & 0.37 \\
\hline $3 r d$ & 0.27 & 0.44 & 0.26 & 0.44 \\
\hline 4th & 0.17 & 0.37 & 0.14 & 0.35 \\
\hline 5 th & 0.2 & 0.4 & 0.13 & 0.33 \\
\hline \multicolumn{5}{|l|}{ Ethnicity (ref: White*, proportion) } \\
\hline Asian - Indian & & & 0.19 & 0.39 \\
\hline Asian - Pakistani & & & 0.22 & 0.42 \\
\hline Asian - Bangladeshi & & & 0.08 & 0.28 \\
\hline Asian - Other & & & 0.07 & 0.25 \\
\hline Black - Caribbean & & & 0.11 & 0.32 \\
\hline Black - African & & & 0.14 & 0.35 \\
\hline Black - other & & & 0.01 & 0.09 \\
\hline Mixed & & & 0.07 & 0.25 \\
\hline Chinese & & & 0.02 & 0.16 \\
\hline Other & & & 0.08 & 0.28 \\
\hline \multicolumn{5}{|l|}{ Religion (ref: Christian, proportion) } \\
\hline Christian & 0.74 & 0.44 & 0.28 & 0.45 \\
\hline Buddhist & $<0.01$ & NA & 0.02 & 0.12 \\
\hline Hindu & $<0.01$ & NA & 0.1 & 0.3 \\
\hline Jewish & $<0.01$ & NA & 0 & 0.03 \\
\hline Muslim & 0.02 & 0.13 & 0.48 & 0.5 \\
\hline Sikh & $<0.01$ & NA & 0.05 & 0.21 \\
\hline Any other & 0.02 & 0.13 & 0.02 & 0.12 \\
\hline No religion & 0.22 & 0.42 & 0.06 & 0.24 \\
\hline Born in the UK (proportion) & 0.93 & 0.25 & 0.35 & 0.48 \\
\hline Married with children (proportion) & 0.47 & 0.5 & 0.49 & 0.5 \\
\hline Lived for 5 years or longer (proportion) & 0.71 & 0.45 & 0.55 & 0.5 \\
\hline English mentioned as main language & 0.98 & 0.15 & 0.59 & 0.49 \\
\hline Rural (proportion) & 0.22 & 0.41 & 0.01 & 0.1 \\
\hline Socio-economic status (ref: Higher and lower management) & 0.36 & 0.48 & 0.22 & 0.42 \\
\hline Intermediate; small employers & 0.29 & 0.45 & 0.21 & 0.4 \\
\hline Semi-routine and routine & 0.26 & 0.44 & 0.25 & 0.43 \\
\hline Other (never work/long-term unemployed/students) & 0.1 & 0.29 & 0.32 & 0.47 \\
\hline \multicolumn{5}{|l|}{ MSOA-level variables } \\
\hline Ethnic Diversity Index & 0.23 & 0.21 & 0.69 & 0.19 \\
\hline Cannot speak English well (pc of those whose 1st language not English) & 18.6 & 7.7 & 23.4 & 8 \\
\hline Married households with dependent children $(p c)$ & 15.4 & 4.4 & 16.7 & 5.7 \\
\hline Percentage of population aged $65+$ & 17.2 & 5.5 & 10.3 & 3.9 \\
\hline Income deprivation score & 0.14 & 0.08 & 0.22 & 0.09 \\
\hline Crime deprivation score & -0.07 & 0.65 & 0.59 & 0.47 \\
\hline Proportion of population from the same ethnic group & 0.82 & 0.24 & 0.15 & 0.16 \\
\hline Proportion of population with the same religion & 0.53 & 0.2 & 0.34 & 0.21 \\
\hline
\end{tabular}

*The "White" category includes White British, White Irish, Gypsy and Irish travellers, and any other White background.

Source: Citizenship Survey, pooled 2009/10-2010/11 (Secure Access), and for the MSOA variables, Census 2011 ONS/DEFRA and CLG, data linked to the Citizenship Survey by MSOA variables. 
Accordingly, we estimate separate models for the white and non-white population.

We estimated three-level models that allow for the clustering of the MSOAs and the LAs with $I=1, \ldots L$ explanatory variables, denoted by $X_{\mathrm{ijkl}}$. The model can be written as:

$$
y_{i j k} \sim \operatorname{Bernoulli}\left(p_{i j k}\right),
$$

and the expectation of the logit-transformed probability $p_{i j k}$ is

$$
\log \left(\frac{p_{i j k}}{1-p_{i j k}}\right)=\operatorname{Logit}\left(p_{i j k}\right)=\beta_{0}+\sum_{l=1}^{L} \beta_{p} X_{i j k l}+u_{0 j k}+v_{0 k}
$$

where $Y_{\mathrm{ijk}}$ is a binary indicator variable taking the value of 1 when the respondent indicated they trust most people in the neighbourhood and 0 if they do not, for respondent (individual) $i$ living in MSOA $j$ that is nested within Local Authority $k$. We define the probability of trusting neighbours as:

$$
p_{i j k}=\operatorname{Prob}\left(y_{i j k}=1\right) \text {, }
$$

where $\beta_{0}$ and $\beta_{l}, I=1, \ldots, P$ are the parameters of the linear regression, $u_{0 \mathrm{jk}}$ and $v_{0 k}$ are the random intercepts that capture the unobserved MSOA and Local Authority heterogeneity. We assume that these random intercepts are Gaussian with zero means and variances $\sigma_{u 0}^{2}$ and $\sigma_{v 0}^{2}$, respectively.

\section{Results}

We estimated three-level models of trust with individuals at Level 1, MSOAs at Level 2 and Local Authorities at Level 3 (see Table 1). As our interest in this paper centres on the immediate neighbourhood correlates of trust we only include variables at the individual and MSOA level in the models. We first tested the significance and direction of association between ethnic diversity and trust (model 1), then added a measure of language ability (model 2). Finally, to test the idea that the effect of ethnic diversity in an area may be conditional on the language proficiency of migrants in an area we include an interaction term between ethnic diversity and English language proficiency (model 3); see Tables 3 and 4.

The means and standard deviations of the individual and neighbourhood variables included in the models are listed in Table 2. Table 2 shows the mean levels of trust (dependent variable) vary substantially between the white and non-white group with around half of white respondents stating they trust most people in their neighbourhood compared to just a quarter of nonwhite respondents. This further justifies the decision to estimate separate models for the white and non-white group. 
Table 3. Individual and MSOA-level variables effect on neighbourhood trust for the White group.

\begin{tabular}{|c|c|c|c|c|c|c|c|c|c|}
\hline & \multicolumn{3}{|c|}{ Model 1} & \multicolumn{3}{|c|}{ Model 2} & \multicolumn{3}{|c|}{ Model 3} \\
\hline & OR & Std. Err. & $p$ & OR & Std. Err. & $p$ & OR & Std. Err. & $p$ \\
\hline Female & 0.85 & 0.04 & $<0.001$ & 0.85 & 0.04 & $<0.001$ & 0.85 & 0.04 & $<0.001$ \\
\hline Survey Year 2010-2011 (ref: 2009-10) & 1.01 & 0.05 & 0.765 & 1.01 & 0.05 & 0.76 & 1.01 & 0.05 & 0.775 \\
\hline Age & 1.02 & 0.00 & $<0.001$ & 1.02 & 0 & $<0.001$ & 1.02 & 0 & $<0.001$ \\
\hline \multicolumn{10}{|l|}{ Income quintiles (ref 1st quintile) } \\
\hline 2nd & 1.1 & 0.08 & 0.173 & 1.1 & 0.08 & 0.171 & 1.1 & 0.08 & 0.173 \\
\hline $3 r d$ & 1.11 & 0.07 & 0.097 & 1.11 & 0.07 & 0.094 & 1.12 & 0.07 & 0.094 \\
\hline 4th & 1.17 & 0.09 & 0.034 & 1.17 & 0.09 & 0.034 & 1.17 & 0.09 & 0.034 \\
\hline 5 th & 1.49 & 0.11 & $<0.001$ & 1.49 & 0.11 & $<0.001$ & 1.49 & 0.11 & $<0.001$ \\
\hline \multicolumn{10}{|l|}{ Religion (ref: Christian) } \\
\hline Buddhist & 1.31 & 0.59 & 0.548 & 1.32 & 0.59 & 0.539 & 1.33 & 0.6 & 0.526 \\
\hline Hindu & 1.92 & 2.91 & 0.666 & 1.97 & 2.99 & 0.656 & 1.94 & 2.94 & 0.662 \\
\hline Jewish & 1.42 & 0.53 & 0.344 & 1.42 & 0.53 & 0.349 & 1.46 & 0.55 & 0.313 \\
\hline Muslim & 0.84 & 0.2 & 0.444 & 0.84 & 0.2 & 0.454 & 0.83 & 0.19 & 0.434 \\
\hline Other & 1.2 & 0.27 & 0.436 & 1.2 & 0.28 & 0.421 & 1.22 & 0.28 & 0.392 \\
\hline No religion & 1.14 & 0.13 & 0.228 & 1.15 & 0.13 & 0.221 & 1.15 & 0.13 & 0.203 \\
\hline Born in the UK & 1.11 & 0.13 & 0.348 & 1.12 & 0.13 & 0.329 & 1.11 & 0.13 & 0.363 \\
\hline Married & 1.28 & 0.05 & $<0.001$ & 1.29 & 0.05 & $<0.001$ & 1.29 & 0.05 & $<0.001$ \\
\hline Main language English & 1.37 & 0.25 & 0.08 & 1.37 & 0.25 & 0.084 & 1.37 & 0.25 & 0.08 \\
\hline Lived for 5 years or longer & 1.09 & 0.05 & 0.058 & 1.1 & 0.05 & 0.057 & 1.1 & 0.05 & 0.055 \\
\hline \multicolumn{10}{|c|}{ Socio-economic status (ref: Higher and lower management) } \\
\hline Intermediate; small employers & 0.79 & 0.04 & $<0.001$ & 0.79 & 0.04 & $<0.001$ & 0.79 & 0.04 & $<0.001$ \\
\hline Semi-routine and routine & 0.61 & 0.04 & $<0.001$ & 0.61 & 0.04 & $<0.001$ & 0.61 & 0.04 & $<0.001$ \\
\hline Other (never work/long-term unemployed/students) & 0.73 & 0.06 & $<0.001$ & 0.73 & 0.06 & $<0.001$ & 0.73 & 0.06 & $<0.001$ \\
\hline Married households with dependent children & 0.99 & 0.01 & 0.478 & 1 & 0.01 & 0.51 & 0.99 & 0.01 & 0.34 \\
\hline Income deprivation score & 0.84 & 0.01 & $<0.001$ & 0.85 & 0.01 & $<0.001$ & 0.84 & 0.01 & $<0.001$ \\
\hline Crime deprivation score & 0.97 & 0.02 & 0.038 & 0.97 & 0.02 & 0.039 & 0.97 & 0.02 & 0.038 \\
\hline Percentage of population aged $65+$ & 1.02 & 0.01 & $<0.001$ & 1.02 & 0.01 & $<0.001$ & 1.02 & 0.01 & 0.001 \\
\hline Rural & 1.49 & 0.1 & $<0.001$ & 1.49 & 0.1 & $<0.001$ & 1.48 & 0.1 & $<0.001$ \\
\hline Proportion of population in the same ethnic group & 0.87 & 0.14 & 0.386 & 0.86 & 0.14 & 0.367 & 0.87 & 0.14 & 0.39 \\
\hline
\end{tabular}


Table 3. Continued.

\begin{tabular}{|c|c|c|c|c|c|c|c|c|c|}
\hline & \multicolumn{3}{|c|}{ Model 1} & \multicolumn{3}{|c|}{ Model 2} & \multicolumn{3}{|c|}{ Model 3} \\
\hline & OR & Std. Err. & $p$ & OR & Std. Err. & $p$ & OR & Std. Err. & $p$ \\
\hline Proportion of population with the same religion & 1.37 & 0.39 & 0.266 & 1.38 & 0.39 & 0.255 & 1.41 & 0.4 & 0.227 \\
\hline Ethnic Diversity Index & 0.64 & 0.13 & 0.031 & 0.63 & 0.13 & 0.028 & 0.44 & 0.18 & 0.04 \\
\hline Cannot speak English well (\%) & & & & 1 & 0 & 0.327 & 0.99 & 0 & 0.151 \\
\hline Ethnic Diversity Index*Cannot speak English well & & & & & & & 1.02 & 0.02 & 0.291 \\
\hline LA var & 0.04 & 0.02 & & 0.04 & 0.02 & & 0.04 & 0.02 & \\
\hline MSOA var & 0.21 & 0.04 & & 0.21 & 0.04 & & 0.21 & 0.04 & \\
\hline $\mathrm{N}$ & df & AIC & $\mathrm{BIC}$ & df & AIC & $\mathrm{BIC}$ & df & AIC & $\mathrm{BIC}$ \\
\hline 13,032 & 31 & 15,655 & 15,887 & 32 & 15,656 & 15,895 & 33 & 15,657 & 15,904 \\
\hline
\end{tabular}

Source: Citizenship Survey, pooled 2009/10-2010/11 (Secure Access), Census 2011, ONS/DEFRA and CLG. Note: OR denotes odds ratio, SE is the standard error of the point estimate. 
Table 4. Individual and MSOA-level variables effect on neighbourhood trust for the non-white group.

\begin{tabular}{|c|c|c|c|c|c|c|c|c|c|}
\hline & \multicolumn{3}{|c|}{ Model 1} & \multicolumn{3}{|c|}{ Model 2} & \multicolumn{3}{|c|}{ Model 3} \\
\hline & $\mathrm{OR}$ & Std. Err. & $p$ & $\mathrm{OR}$ & Std. Err. & $p$ & $\mathrm{OR}$ & Std. Err. & $p$ \\
\hline Female & 0.78 & 0.04 & $<0.001$ & 0.78 & 0.04 & $<0.001$ & 0.78 & 0.04 & $<0.001$ \\
\hline Survey Year 2010-2011 (ref: 2009-10) & 0.85 & 0.04 & 0.001 & 0.85 & 0.04 & 0.001 & 0.85 & 0.04 & 0.002 \\
\hline Age & 1.01 & 0 & $<0.001$ & 1.01 & 0 & $<0.001$ & 1.01 & 0 & $<0.001$ \\
\hline \multicolumn{10}{|l|}{ Income quintiles (ref: 1st quintile) } \\
\hline 2nd & 0.79 & 0.06 & 0.001 & 0.78 & 0.06 & 0.001 & 0.78 & 0.06 & 0.001 \\
\hline 3 rd & 0.87 & 0.06 & 0.043 & 0.87 & 0.06 & 0.043 & 0.87 & 0.06 & 0.041 \\
\hline 4th & 0.75 & 0.06 & 0.001 & 0.76 & 0.06 & 0.001 & 0.76 & 0.06 & 0.001 \\
\hline 5 th & 1.03 & 0.09 & 0.717 & 1.04 & 0.09 & 0.664 & 1.04 & 0.09 & 0.683 \\
\hline \multicolumn{10}{|l|}{ Ethnicity (ref: Asian Indian) } \\
\hline Asian - Pakistani & 1.08 & 0.11 & 0.46 & 1.06 & 0.11 & 0.54 & 1.06 & 0.11 & 0.548 \\
\hline Asian - Bangladeshi & 0.85 & 0.11 & 0.222 & 0.85 & 0.11 & 0.201 & 0.85 & 0.11 & 0.204 \\
\hline Asian - Other & 0.87 & 0.1 & 0.251 & 0.87 & 0.1 & 0.247 & 0.88 & 0.1 & 0.287 \\
\hline Black - Caribbean & 0.8 & 0.1 & 0.078 & 0.79 & 0.1 & 0.066 & 0.8 & 0.1 & 0.082 \\
\hline Black - African & 0.91 & 0.11 & 0.44 & 0.92 & 0.11 & 0.441 & 0.92 & 0.11 & 0.496 \\
\hline Black - other & 0.54 & 0.17 & 0.056 & 0.54 & 0.17 & 0.055 & 0.54 & 0.17 & 0.056 \\
\hline Mixed & 0.98 & 0.13 & 0.882 & 0.97 & 0.13 & 0.84 & 0.98 & 0.13 & 0.904 \\
\hline Chinese & 0.98 & 0.18 & 0.897 & 0.98 & 0.18 & 0.892 & 0.99 & 0.18 & 0.955 \\
\hline Other & 0.69 & 0.09 & 0.004 & 0.69 & 0.09 & 0.003 & 0.7 & 0.09 & 0.004 \\
\hline \multicolumn{10}{|l|}{ Religion (ref: Christian) } \\
\hline Buddhist & 1.06 & 0.24 & 0.795 & 1.06 & 0.24 & 0.802 & 1.04 & 0.24 & 0.861 \\
\hline Hindu & 1 & 0.14 & 0.998 & 0.99 & 0.14 & 0.946 & 0.99 & 0.14 & 0.942 \\
\hline Jewish & 1.21 & 0.89 & 0.792 & 1.22 & 0.89 & 0.787 & 1.2 & 0.88 & 0.807 \\
\hline Muslim & 1.13 & 0.12 & 0.245 & 1.12 & 0.12 & 0.281 & 1.12 & 0.12 & 0.287 \\
\hline Sikh & 1.29 & 0.22 & 0.132 & 1.26 & 0.21 & 0.174 & 1.24 & 0.21 & 0.199 \\
\hline Other & 1.4 & 0.3 & 0.117 & 1.39 & 0.3 & 0.126 & 1.36 & 0.29 & 0.15 \\
\hline No religion & 1.41 & 0.17 & 0.005 & 1.41 & 0.17 & 0.005 & 1.4 & 0.17 & 0.006 \\
\hline Born in the UK & 0.87 & 0.05 & 0.024 & 0.87 & 0.05 & 0.021 & 0.87 & 0.05 & 0.02 \\
\hline Married & 1.12 & 0.06 & 0.026 & 1.12 & 0.06 & 0.03 & 1.12 & 0.06 & 0.03 \\
\hline Main language English & 0.99 & 0.05 & 0.82 & 0.99 & 0.06 & 0.877 & 0.99 & 0.06 & 0.897 \\
\hline
\end{tabular}


Table 4. Continued.

\begin{tabular}{|c|c|c|c|c|c|c|c|c|c|}
\hline & \multicolumn{3}{|c|}{ Model 1} & \multicolumn{3}{|c|}{ Model 2} & \multicolumn{3}{|c|}{ Model 3} \\
\hline & OR & Std. Err. & $p$ & OR & Std. Err. & $p$ & OR & Std. Err. & $p$ \\
\hline $\begin{array}{l}\text { Lived for } 5 \text { years or longer } \\
\text { Socio-economic status (ref: Higher and lower management) }\end{array}$ & 1.22 & 0.06 & $<0.001$ & 1.22 & 0.06 & $<0.001$ & 1.22 & 0.06 & $<0.001$ \\
\hline Intermediate; small employers & 0.8 & 0.06 & 0.003 & 0.8 & 0.06 & 0.003 & 0.8 & 0.06 & 0.003 \\
\hline Semi-routine and routine & 0.67 & 0.05 & $<0.001$ & 0.66 & 0.05 & $<0.001$ & 0.66 & 0.05 & $<0.001$ \\
\hline Other (never work/long-term unemployed/students) & 0.77 & 0.06 & 0.001 & 0.77 & 0.06 & 0.001 & 0.77 & 0.06 & 0.001 \\
\hline Married households with dependent children & 1.02 & 0.01 & 0.003 & 1.02 & 0.01 & 0.061 & 1.01 & 0.01 & 0.313 \\
\hline Income deprivation score & 0.92 & 0.02 & $<0.001$ & 0.89 & 0.02 & $<0.001$ & 0.88 & 0.02 & $<0.001$ \\
\hline Crime deprivation score & 0.96 & 0.02 & 0.069 & 0.96 & 0.02 & 0.037 & 0.96 & 0.02 & 0.035 \\
\hline Percentage of population aged $65+$ & 1.03 & 0.01 & 0.001 & 1.03 & 0.01 & 0.005 & 1.03 & 0.01 & 0.012 \\
\hline Rural & 1.72 & 0.4 & 0.02 & 1.75 & 0.4 & 0.016 & 1.56 & 0.36 & 0.059 \\
\hline Proportion of population in the same ethnic group & 1.11 & 0.28 & 0.693 & 1.04 & 0.27 & 0.872 & 1.12 & 0.29 & 0.665 \\
\hline Proportion of population with the same religion & 1.22 & 0.26 & 0.348 & 1.21 & 0.25 & 0.363 & 1.19 & 0.25 & 0.418 \\
\hline Ethnic Diversity Index & 0.63 & 0.15 & 0.06 & 0.6 & 0.14 & 0.03 & 0.15 & 0.07 & $<0.001$ \\
\hline Cannot speak English well (\%) & & & & 1.02 & 0.01 & 0.013 & 0.98 & 0.01 & 0.142 \\
\hline Ethnic Diversity Index*Cannot speak English well & & & & & & & 1.07 & 0.02 & 0.001 \\
\hline LA var & 0.12 & 0.04 & & 0.1 & 0.03 & & 0.09 & 0.03 & \\
\hline MSOA var & 0.29 & 0.05 & & 0.28 & 0.05 & & 0.28 & 0.05 & \\
\hline $\mathrm{N}$ & $\mathrm{df}$ & AIC & BIC & $\mathrm{df}$ & AIC & BIC & df & AIC & BIC \\
\hline 11,781 & 41 & 12,309 & 12,611 & 42 & 12,305 & 12,615 & 43 & 12,297 & 12,614 \\
\hline
\end{tabular}


Table 3 shows the odds ratio (OR) of neighbour trust for the white group with a given set of individual and neighbourhood characteristics. The constant has been suppressed in all results. The findings show that individuallevel characteristics account for most of the variation in neighbour trust: increases in age, socio-economic class and length of residence are associated with increases in trust.

The bottom half of Table 3 shows different effects of neighbourhood characteristics on neighbour trust for the white group. Neighbourhoods within urban areas and those with higher income and crime neighbourhood deprivation are negatively associated with trust. In contrast, neighbourhoods with a higher proportion of elderly population and families (married people with children) exhibit higher levels of trust, compared to those with younger populations, and a lower proportion of family households. In line with previous studies examining the effects of ethnic diversity on local social cohesion (see van der Meer and Tolsma (2014) for a review) our findings demonstrate that higher levels of neighbourhood ethnic diversity are associated with lower neighbour trust (Model 1). To explore the cultural differentiation explanation for the negative association between ethnic diversity and trust, we tested if being among migrants who cannot speak English well affects trust towards neighbours, and if the effect of ethnic diversity on trust depends on the levels of language fluency among migrants in the community. Our results do not support either of these propositions as indicated by the non-significant main effect of language fluency and the non-significant interaction between language fluency and ethnic diversity (models 2 and 3).

Table 4 shows different effects of individual and neighbourhood characteristics on neighbour trust for the non-white group. The results show that increases in income are associated with lower probabilities of trust for the non-white group. Living in a rural area has a more noticeable effect on trust for the non-white group, and the effect of neighbourhood deprivation on trust is smaller, than for white groups. The effect of ethnic diversity on trust is still negative (model 1 ).

However, after the inclusion of English language proficiency in the community (Model 2) the results show that non-white groups report lower trust in neighbourhoods with higher levels of diversity but higher levels of trust in neighbourhoods with a higher proportion of migrants who cannot speak English well. That is, with an increase of the percentage of migrants who cannot speak English well in a community by one percentage point, the predicted odds of trusting many of the people in the neighbourhood increase by around 2 per cent (OR $=1.02, p=0.013)$.

In the next model (model 3), we included an interaction term between the proportion of migrants who cannot speak English well in the neighbourhood and levels of ethnic diversity to examine whether migrants' ability to speak the majority language moderates the relationship between ethnic diversity 
and trust and found the interaction term to be significant with a very small $p$ value. As the interaction term is positive, the odds are that neighbour trust is higher in ethnically diverse areas where there is also a higher proportion of migrants who cannot speak English well compared to equally ethnically diverse areas with a lower proportion of migrants who cannot speak English well.

To understand the relationship between diversity, language ability and trust for both the white and non-white groups we calculated the marginal predictive means (MPMs) of the expected levels of trust for combinations of the two variables at their minimum and maximum values and plotted scores for the white (Figure 1) and non-white (Figure 2) groups. Examining the non-white group first (Figure 2), it can be seen that in neighbourhoods with a high (47.4 per cent, a maximum in the sample) proportion of migrants who cannot speak English well (red line) there is a positive relationship between ethnic diversity and trust. However, in neighbourhoods with low proportions of migrants who cannot speak English well (blue line; 2.17 per cent) the slope is significant (non-overlapping Cls for MPMs of the blue line) and negative. Our model results show that for the non-white population, in areas with very low ethnic diversity, poor English language ability does not impact trust. In neighbourhoods with a high concentration of migrants who cannot speak English well, trust increases with increases in ethnic diversity levels (i.e. the Cls for MPMs between red and blue lines for Ethnic Diversity Index $=0.89$ do not overlap), while in neighbourhoods with a lower concentration of migrants, trust decreases with increases in ethnic diversity levels. In other words, the concentration of immigrants with poor language ability in the majority language in ethnically diverse areas is associated with relatively higher trust for the non-white group, than in ethnically homogeneous areas. This effect is not evident for the white group, where we observe trust decreasing with increases in ethnic diversity irrespective of community level of language ability in the majority language (Figure 1). This is indicated by the almost flat red line in Figure 1 that shows trust levels not varying significantly (clearly overlapping 95 per cent Cls) for all values of the Ethnic Diversity Index ranging from 0.024 to 0.89 for the high proportion of migrants who cannot speak English well (47.4 per cent). A small decrease in trust is observed for the lowest proportion of migrants with poor language ability (2.17 per cent) that is also indicated by a significant OR for the main effect of the Ethnic Diversity Index (Table 3; model 3).

In sum, these results suggest that trust levels for the white group are lower in ethnically diverse areas irrespective of how well English is spoken in the community. However, for non-white groups increases in ethnic diversity can increase or decrease trust depending on levels of language proficiency. Higher levels of trust in ethnically diverse areas with low levels of language proficiency (compared to those with high levels of language proficiency) 


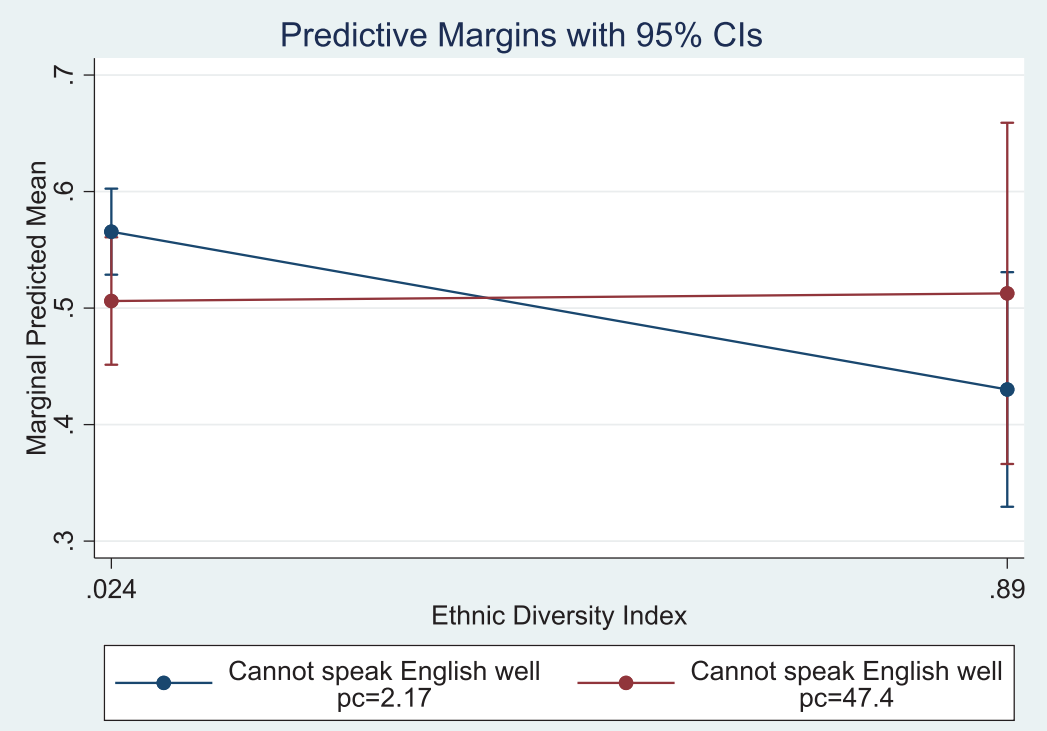

Figure 1. Marginal predictive means of the levels of trust for the white group. Source: own calculations based on Citizenship Survey, pooled 2009/10-2010/11 (Secure Access) and Census 2011, ONS/DEFRA and CLG.

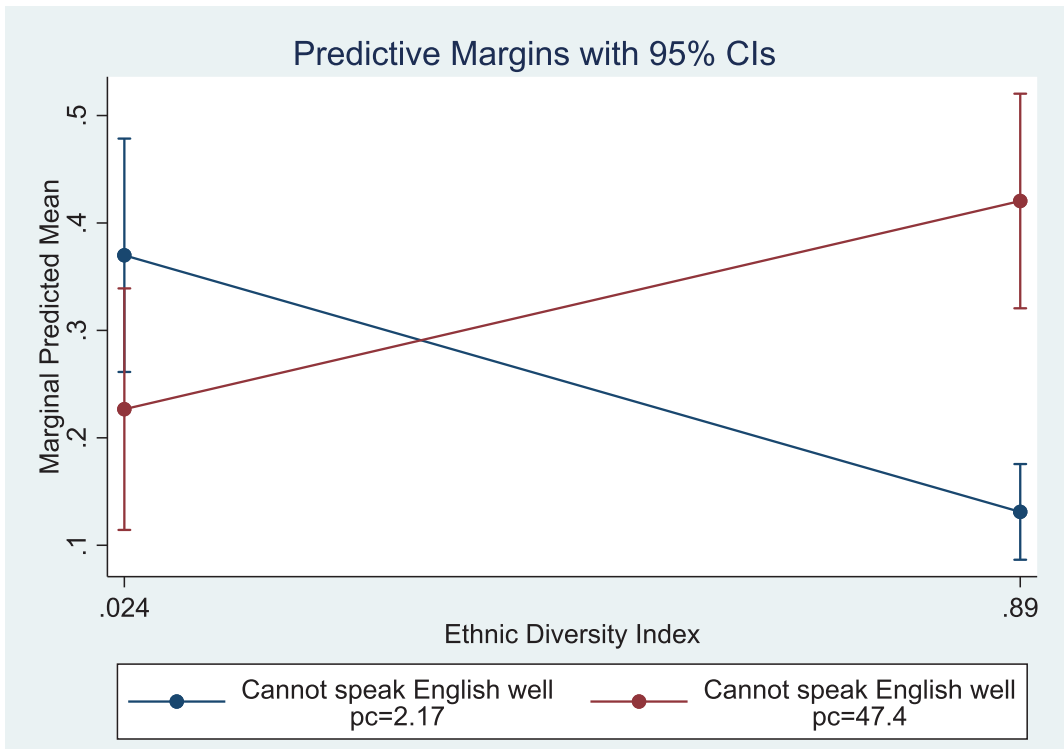

Figure 2. Marginal predictive means of the levels of trust for the non-white group. Source: own calculations based on Citizenship Survey, pooled 2009/10-2010/11 (Secure Access) and Census 2011, ONS/DEFRA and CLG. 
suggest that non-white groups in areas with a stronger immigrant identity may be more trusting than those in more-established ethnic minority areas. Post-hoc analyses show differences in trust levels between the non-white UK-born and non-UK-born groups providing some support for this explanation. For the non-UK-born group (first-generation migrants) trust increases with increases in ethnic diversity in areas where migrants can't speak English well. However, for the UK-born non-white group this is not the case.

Additional validation analyses are presented in the Appendix. We observe that the results of the analysis are robust to various specifications of the models. The models test for quadratic effects of neighbourhood ethnic diversity and language ability (Models 3.1 and 3.3 in the Appendix) and additional interactions (3.2-3.3) which were not significant and did not alter the substantive results of the model. We also estimated ordered logit regression models with all four categories of trust (for the non-White, Model 4 in the Appendix) and the results agree with those of Model 3 showing language proficiency in an area to moderate the effects of diversity on trust. Similar conclusions about the robustness of the analysis for the White population were reached when we estimated ordered logit regression models (not shown). Taken together, these results point to the importance of shared experience of immigration, rather than majority language, for trust.

\section{Discussion}

Existing studies in the UK that consider the impact of ethnic diversity on trust have drawn on ethnic categorical differences, cognitive biases, and racial threat to test the constrict hypothesis. The analysis presented in this paper builds on existing research by examining the effect of cultural differentiation on neighbourhood trust associated with linguistic diversity. Our results show that for the white group increases in ethnic diversity lower trust, and this effect does not depend on how well English is spoken among immigrants in the community. For the non-white group, we show that the effect of ethnic diversity on trust depends on migrants' language ability in the majority language. In neighbourhoods where migrants cannot speak English well, trust increases as ethnic diversity increases. In contrast, in neighbourhoods where migrants can speak English well, higher ethnic diversity lowers trust. These results hold after we control for individual and neighbourhood demographic and socio-economic status factors such as deprivation (alongside measures of co-ethnic and co-religion density). The adverse effect of ethnic diversity on trust does not therefore appear to be due to cultural differentiation and linguistic diversity, and the mechanism of anomie, and anxieties about the existence of shared societal norms and moral values.

The present study is not without limitations. As with all cross-sectional studies we cannot infer causality from the observed associations. 
The association between diversity and trust is complicated by the potential influence of self-selection, that is, that immigrants' residential choices are likely to be constrained to disadvantaged urban areas characterized by lower trust and cohesion, and reveal preference to live among co-ethnics, so that residential sorting may drive differences in levels of trust across communities (Laurence and Bentley 2015). This however does not undermine the key finding that the association between ethnic diversity and trust for nonwhite groups depends on language ability in the community. Future research should utilize longitudinal and experimental designs to further explore the causality of observed associations.

Even though our results are not conclusive of the mechanisms involved in increasing trust in some ethnically diverse areas they do suggest that the composition of ethnic diversity and the way diversity is organized matters for trust and cohesion. While it is likely that coordination problems and lack of shared participation and meaning can hinder trust in some neighbourhood contexts, in others, it might not be a precondition to establishing social relations and trust. Evidence from qualitative studies (Bynner 2019; Wessendorf 2016; Mintchev and Moore 2018) has increasingly shown that in superdiverse places characterized by a large number of (smaller) ethnic groups with a multiplicity of social, economic and cultural characteristics (Vertovec 2007), the relationship between diversity and cohesion "plays out in a radically different way" (Mintchev and Moore 2018). Wessendorf (2016) ascertains that superdiverse communities shaped by recent patterns of immigration and linguistic diversity may not necessarily be characterized by low levels of cohesion since everyone is different, and no group is large enough or consolidated enough to pose a threat to others. In ethnically diverse areas people may find it easier to communicate with people from different backgrounds because linguistic diversity creates an environment where people are used to hearing different accents and dealing with people who cannot speak English well (Wessendorf 2018). The absence of "politics of belonging" (Pemberton 2017) means that social tensions may not be organized on the grounds of ethnic differences, but rather on the basis of economic, social and symbolic inequalities (Bynner 2019; Mintchev and Moore 2018). Shared experience of immigration rather than shared "majority" language, together with shared interests on the basis of social class and other socio-economic characteristics (Wessendorf 2014) may therefore be more important in building friendships and social connections needed to establish trust. When immigrants lose their shared immigrant identity (e.g. second generation migrants plus), ethnic identity and hierarchies may come into play and intensify preexisting socio-economic divisions lowering trust. These propositions have been largely overlooked by the quantitative literature on ethnic diversity and social cohesion and warrant further investigation. A promising future research direction would be to examine the effect of ethnic diversity on 
trust in different ethnic diversity contexts such as super diverse "new immigration" driven neighbourhoods, and ethnically diverse neighbourhoods with large populations of established ethnic minority groups. The development of measures of ethnic diversity that take into account the nuances of ethnic diversity and immigration can advance understanding about the different ways ethnic diversity can impact on social cohesion in local communities (Lymperopoulou 2020). Ability to speak the majority language may be more important for establishing trust in neighbourhoods with little recent experience of immigration (where minority groups are more settled), a hypothesis that seems to be supported by our results. Research examining the cultural threat hypothesis shows that changes in ethnic diversity (rather than ethnic diversity per se) driven by large inflows of immigrants instigate higher feelings of threat in communities with little pre-existing immigration but will be less threatening in areas with higher levels of ethnic diversity (Newman 2013).

One implication of our findings is that the cultural characteristics of ethnic diversity are important in facilitating interpretation and assessments of the impact of immigration and ethnic diversity on local communities needed to guide policies aimed at improving social cohesion.

\section{Disclosure statement}

No potential conflict of interest was reported by the author(s).

\section{Funding}

This work is supported by the Economic and Social Research Council [grant number ES/P009301/1].

\section{ORCID}

Kitty Lymperopoulou (D) http://orcid.org/0000-0003-0796-5027

Arkadiusz Wiśniowski (D) http://orcid.org/0000-0002-7567-3600

James Laurence (D) http://orcid.org/0000-0002-3412-2431

\section{References}

Abascal, M., and D. Baldassarri. 2015. "Love Thy Neighbor? Ethnoracial Diversity and Trust Reexamined." American Journal of Sociology 121: 722-782.

Allport, G. W. 1954. The Nature of Prejudice. Cambridge, MA: Addison-Wesley.

Becares, L., M. Stafford, J. Laurence, and J. Nazroo. 2011. “Composition, Concentration and Deprivation: Exploring Their Association with Social Cohesion Among Different Ethnic Groups in the UK." Urban Studies 48 (13): 2771-2787.

Blalock, H. M. 1967. Toward a Theory of Minority-Group Relations. New York: John Wiley and Sons. 
Bynner, C. 2019. "Intergroup Relations in a Super-Diverse Neighbourhood: The Dynamics of Population Composition Context and Community." Urban Studies 56 (2): 335-351.

Casey, L. 2016. The Casey Review: A Review Into Opportunity and Integration. London: Department of Communities and Local Government.

Cheong, P., R. Edwards, H. Gouldbourne, and J. Solomos. 2007. "Immigration, Social Cohesion and Social Capital, A Critical Review." Critical Social Policy 2: 24-49.

Commission on Integration and Cohesion. 2007. Our Shared Future. Commission on Integration and Cohesion. London: CLG.

Department for Communities and Local Government. 2011. 2010-11 Citizenship Survey: Technical Report. London: Communities and Local Government.

de Vroome, T., B. Martinovic, and M. Verkuyten. 2014. "The Integration Paradox: Level of Education and Immigrants' Attitudes Towards Natives and the Host Society." Cultural Diversity \& Ethnic Minority Psychology 20: 166-175.

Druckman, J. N., C. L. Hennessy, K. St. Charles, et al. 2010. “Competing Rhetoric Over Time: Frames Versus Cues." The Journal of Politics 72 (1): 136-148.

Enos, R. D. 2014. "Causal Effect of Intergroup Contact on Exclusionary Attitudes." Proceedings of the National Academy of Sciences 111 (10): 3699-3704.

Ford, R., and M. Goodwin. 2014. Revolt on the Right. Abindgon: Routledge.

Ford, R., and K. Lymperopoulou. 2017. "Immigration: How Attitudes in the UK Compare with Europe." In British Social Attitudes: The 34th Report, edited by E. Clery, J. Curtice, and R. Harding, 1-30. London: NatCen Social Research.

Gundelach, B., and M. Freitag. 2014. "Neighbourhood Diversity and Social Trust: An Empirical Analysis of Interethnic Contact and Group-Specific Effects." Urban Studies 51 (6): 1236-1256.

HM Government. 2018. Integrated Communities Strategy Green Paper. London: Ministry of Housing, Communities \& Local Government.

Hopkins, D. J., V. C. Tran, and A. F. Williamson. 2014. "See No Spanish: Language, Local Context, and Attitudes Toward Immigration." Politics, Groups, and Identities 2 (1): 35-51.

Huijts, T., G. Kraaykamp, and P. Scheepers. 2014. "Ethnic Diversity and Informal Intraand Inter-Ethnic Contacts with Neighbours in The Netherlands: A Comparison of Natives and Ethnic Minorities." Acta Sociologica 57: 41-57.

Department for Communities and Local Government and Ipsos MORI. 2012a. Citizenship Survey, 2009-2010. [Data Collection]. UK Data Service. SN: 6733.

Department for Communities and Local Government and Ipsos MORI. 2012b. Citizenship Survey, 2010-2011. [data collection]. UK Data Service. SN: 7111.

Kaufmann, E., and G. Harris. 2015. "'White Flight' or Positive Contact? Local Diversity and Attitudes to Immigration in Britain." Comparative Political Studies 48 (12): 1563-1590.

Koopmans, R., and M. Schaeffer. 2015. "Relational Diversity and Neighbourhood Cohesion. Unpacking Variety, Balance and In-Group Size." Social Science Research 53: 162-176.

Lancee, B., and J. Dronkers. 2011. "Ethnic, Religious and Economic Diversity in Dutch Neighbourhoods: Explaining Quality of Contact with Neighbours, Trust in the Neighbourhood and Inter-Ethnic Trust." Journal of Ethnic and Migration Studies 37: 597-618.

Larsen, K. S., K. Krumov, H. Van Le, et al. 2009. "Threat Perception and Attitudes Toward Documented and Undocumented Immigrants in the United States: Framing the Debate and Conflict Resolution." European Journal of Social Sciences 7 (4): 115-134. 
Laurence, J. 2011. "The Effect of Ethnic Diversity and Community Disadvantage on Social Cohesion: A Multi-Level Analysis of Social Capital and Interethnic Relations in UK Communities." European Sociological Review 27: 70-89.

Laurence, J. 2017. "Wider-Community Segregation and the Effect of Neighbourhood Ethnic Diversity on Social Capital: An Investigation Into Intra-Neighbourhood Trust in Great Britain and London." Sociology 51: 1011-1033.

Laurence, J., and B. Bentley. 2017. "Does Ethnic Diversity Have a Negative Effect on Attitudes Towards the Community? A Longitudinal Analysis of the Causal Claims Within the Ethnic Diversity and Social Cohesion Debate." European Sociological Review 32: 54-67.

Laurence, J., and A. Heath. 2008. Predictors of Community Cohesion, Multi-Level Modelling of the 2005 Citizenship Survey. London: CLG.

Laurence, J., and H. H. Kim. 2021. "Foreign-Born Population Growth, Negative Outgroup Contact, and Americans' Attitudes Towards Legal and Unauthorized Immigration." Political Studies, doi:10.1177/00323217211005920.

Leigh, A. 2006. "Trust, Inequality and Ethnic Heterogeneity." The Economic Record 82 (258): 26880.

Letki, N. 2008. “Does Diversity Erode Social Cohesion? Social Capital and Race in British Neighbourhoods." Political Studies 56: 99-126.

Levrau, F., and P. Loobuyck. 2013. "Is Multiculturalism Bad for Social Cohesion and Redistribution?" The Political Quarterly 84: 101-109.

Lymperopoulou, K. 2020. "Immigration and Ethnic Diversity in England and Wales Examined Through an Area Classification Framework." Journal of International Migration and Integration 21: 829-846.

Lymperopoulou, K., and A. Wiśniowski. 2019. "Annex: Independent Statistical Report, An Investigation of the Area Determinants of Trust Using the Citizenship Survey 2009-11." In Distant Neighbours? Understanding and Measuring Social Integration in England, edited by R. Shorthouse, S. Lampier, and A. Sarygulov, 138-167. London: Bright Blue.

Mintchev, N., and H. L. Moore. 2018. "Super-Diversity and the Prosperous Society." European Journal of Social Theory 21: 117-134.

Newman, B. J. 2013. "Acculturating Contexts and Anglo Opposition to Immigration in the United States." American Journal of Political Science 57 (2): 374-390.

Office for National Statistics. 2013. "2011 Rural-Urban Classification for Small Area Geographies: A User Guide." Available online at https://www.ons.gov.uk/ methodology/geography/geographicalproducts/ruralurbanclassifications/ 2011 ruralurbanclassification

Office for National Statistics. 2020. 2011 Census: Aggregate Data. [data collection]. UK Data Service. SN: 7427.

Pemberton, S. 2017. The Importance of Super-Diverse Places in Shaping Residential Mobility Patterns. A Report to the Leverhulme Trust. Keele: Keele University.

Pemberton, S., and J. Phillimore. 2018. "Migrantplace-Making in Super-Diverse Neighbourhoods: Moving beyond Ethno-National Approaches." Urban Studies 55 (4): 733-750.

Putnam, R. D. 2000. Bowling Alone: The Collapse and Revival of American Community. New York: Simon \& Schuster.

Putnam, R. D. 2007. "E Pluribus Unum: Diversity and Community in the Twenty-First Century. The 2006 Johan Skytte Prize Lecture." Scandinavian Political Studies 30: 137-174.

Quillian, L. 1995. "Prejudice as a Response to Perceived Group Threat, Population Composition and Anti-Immigrant and Racial Prejudice in Europe." American Sociological Review 60: 586-611. 
Robinson, D. 2010. "The Neighbourhood Effects of New Immigration." Environment and Planning A42 (10): 2451-2466.

Robinson, D. and K. Reeve. 2006. Neighbourhood Experiences of New Immigration, Reflections from the Evidence Base. York: Joseph Rowntree Foundation.

Schaeffer, M. 2013. "Can Competing Diversity Indices Inform Us About Why Ethnic Diversity Erodes Social Cohesion? A Test of Five Diversity Indices in Germany." Social Science Research 42: 755-774.

Schmid, K., A. A. Ramiah, and M. Hewstone. 2014. "Neighborhood Ethnic Diversity and Trust: The Role of Intergroup Contact and Perceived Threat." Psychological Science 25 (3): 665-674.

Simpson, E. H. 1949. "Measurement of Diversity." Nature 163: 688.

Smith, T., M. Noble, S. Noble, G. Wright, D. McLennan, and E. Plunkett. 2015. The English Indices of Deprivation 2015: Technical Report. London: Department for Communities and Local Government.

Sturgis, P., I. Brunton-Smith, J. Kuha, and J. Jackson. 2014. "Ethnic Diversity, Segregation and the Social Cohesion of Neighbourhoods in London." Ethnic and Racial Studies 37 (8): 1286-1309.

Sturgis, P., I. Brunton-Smith, S. Read, and N. Allum. 2011. "Does Ethnic Diversity Erode Trust? Putnam's Hunkering Down? Thesis Reconsidered." British Journal of Political Science 41: 57-82.

Sturgis, P., and P. Smith. 2010. "Assessing the Validity of Generalized Trust Questions: What Kind of Trust Are We Measuring?" International Journal of Public Opinion Research 22: 74-92.

Tolsma, J., and T. van der Meer. 2017. "Losing Wallets, Retaining Trust? The Relationship Between Ethnic Heterogeneity and Trusting Coethnic and NonCoethnic Neighbours and Non-Neighbours to Return a Lost Wallet." Social Indicators Research 131: 631-658.

van der Meer, T., and J. Tolsma. 2014. "Ethnic Diversity and Its Effects on Social Cohesion." Annual Review of Sociology 40: 459-478.

Vertovec, S. 2007. "Super-Diversity and Its Implications." Ethnic and Racial Studies 30 (6): 1024-1054..

Vertovec, S. 2019. "Talking Around Super-Diversity." Ethnic and Racial Studies 42 (1): 125-139.

Wessendorf, S. 2014. Commonplace Diversity: Social Relations in a Super-Diverse Context. Basingstoke: Palgrave Macmillan.

Wessendorf, S. 2016. "Settling in a Super-Diverse Context: Recent Migrants' Experiences of Conviviality." Journal of Intercultural Studies 37: 449-463.

Wessendorf, S. 2018. Pathways of Settlement among Recent Migrants in Super-diverse Areas, IRIS Working Paper Series, No. 25/2018.

Zetter, R., D. Griffiths, N. Sigona, D. Flynn, T. Pasha, and R. Beynon. 2006. Immigration, Social Cohesion and Social Capital, What are the Links? York: Joseph Rowntree Foundation.

Ziller, C. 2017. "Equal Treatment Regulations and Ethnic Minority Social Trust." European Sociological Review 33 (4): 563-575.

Ziller, C., and C. Spörlein. 2020. "Residential Segregation and Social Trust of Immigrants and Natives: Evidence from the Netherlands." Frontiers in Sociology 5: 45. 


\section{Appendix}

Table A1. Robustness check models.

\begin{tabular}{|c|c|c|c|c|c|c|c|c|c|c|c|c|}
\hline & \multicolumn{3}{|c|}{ Model 3.1} & \multicolumn{3}{|c|}{ Model 3.2} & \multicolumn{3}{|c|}{ Model 3.3} & \multicolumn{3}{|c|}{ Model 4} \\
\hline & $\mathrm{OR}$ & Std. Err. & $p$ & OR & Std. Err. & $p$ & $\mathrm{OR}$ & Std. Err. & $p$ & OR & Std. Err. & $p$ \\
\hline Female & 0.78 & 0.04 & $<0.001$ & 0.78 & 0.04 & $<0.001$ & 0.78 & 0.04 & $<0.001$ & 0.78 & 0.03 & $<0.001$ \\
\hline Survey Year 2010-2011 (ref: 2009-10) & 0.86 & 0.04 & 0.002 & 0.85 & 0.04 & 0.002 & 0.85 & 0.04 & 0.002 & 0.91 & 0.04 & 0.019 \\
\hline Age & 1.01 & 0 & $<0.001$ & 1.01 & 0 & $<0.001$ & 1.01 & 0 & $<0.001$ & 1.01 & 0 & $<0.001$ \\
\hline \multicolumn{13}{|l|}{ Income quartile } \\
\hline 2nd & 0.79 & 0.06 & 0.001 & 0.79 & 0.06 & 0.001 & 0.79 & 0.06 & 0.001 & 0.83 & 0.05 & 0.001 \\
\hline $3 r d$ & 0.87 & 0.06 & 0.041 & 0.87 & 0.06 & 0.044 & 0.87 & 0.06 & 0.043 & 0.97 & 0.05 & 0.511 \\
\hline 4 th & 0.76 & 0.06 & 0.001 & 0.76 & 0.06 & 0.001 & 0.76 & 0.06 & 0.001 & 0.84 & 0.05 & 0.006 \\
\hline 5 th & 1.03 & 0.09 & 0.714 & 1.04 & 0.09 & 0.686 & 1.03 & 0.09 & 0.713 & 1.11 & 0.08 & 0.137 \\
\hline \multicolumn{13}{|l|}{ Ethnicity (ref: Asian Indian) } \\
\hline Asian - Pakistani & 1.06 & 0.11 & 0.58 & 1.05 & 0.11 & 0.636 & 1.06 & 0.11 & 0.585 & 1.02 & 0.08 & 0.802 \\
\hline Asian - Bangladeshi & 0.84 & 0.11 & 0.187 & 0.85 & 0.11 & 0.203 & 0.84 & 0.11 & 0.196 & 0.9 & 0.09 & 0.294 \\
\hline Asian - Other & 0.88 & 0.1 & 0.262 & 0.87 & 0.1 & 0.249 & 0.88 & 0.1 & 0.278 & 0.88 & 0.08 & 0.177 \\
\hline Black - Caribbean & 0.8 & 0.1 & 0.08 & 0.79 & 0.1 & 0.066 & 0.8 & 0.1 & 0.087 & 0.81 & 0.08 & 0.032 \\
\hline Black - African & 0.92 & 0.11 & 0.491 & 0.92 & 0.11 & 0.452 & 0.93 & 0.11 & 0.504 & 0.94 & 0.08 & 0.479 \\
\hline Black - other & 0.54 & 0.17 & 0.056 & 0.53 & 0.17 & 0.053 & 0.54 & 0.17 & 0.056 & 0.61 & 0.13 & 0.025 \\
\hline Mixed & 0.98 & 0.13 & 0.855 & 0.97 & 0.13 & 0.821 & 0.98 & 0.13 & 0.906 & 0.83 & 0.09 & 0.086 \\
\hline Chinese & 0.98 & 0.18 & 0.895 & 0.98 & 0.18 & 0.891 & 0.98 & 0.18 & 0.896 & 1.15 & 0.17 & 0.34 \\
\hline Other & 0.69 & 0.09 & 0.003 & 0.69 & 0.09 & 0.003 & 0.69 & 0.09 & 0.003 & 0.75 & 0.07 & 0.002 \\
\hline \multicolumn{13}{|l|}{ Religion (ref: Christian) } \\
\hline Buddhist & 1.03 & 0.23 & 0.912 & 1.01 & 0.23 & 0.969 & 1.03 & 0.24 & 0.897 & 1.25 & 0.21 & 0.192 \\
\hline Hindu & 0.98 & 0.14 & 0.886 & 0.98 & 0.14 & 0.869 & 0.98 & 0.14 & 0.901 & 1.03 & 0.11 & 0.757 \\
\hline Jewish & 1.17 & 0.86 & 0.831 & 1.18 & 0.86 & 0.822 & 1.19 & 0.87 & 0.81 & 1.85 & 1.02 & 0.262 \\
\hline Muslim & 1.11 & 0.12 & 0.314 & 1.1 & 0.12 & 0.38 & 1.12 & 0.12 & 0.302 & 1.15 & 0.09 & 0.075 \\
\hline Sikh & 1.23 & 0.21 & 0.214 & 1.24 & 0.21 & 0.209 & 1.23 & 0.21 & 0.215 & 1.25 & 0.17 & 0.1 \\
\hline Other & 1.35 & 0.29 & 0.164 & 1.34 & 0.29 & 0.173 & 1.35 & 0.29 & 0.165 & 1.38 & 0.23 & 0.057 \\
\hline No religion & 1.38 & 0.17 & 0.008 & 1.38 & 0.17 & 0.009 & 1.39 & 0.17 & 0.008 & 1.29 & 0.12 & 0.007 \\
\hline
\end{tabular}


Table A1. Continued.

\begin{tabular}{|c|c|c|c|c|c|c|c|c|c|c|c|c|}
\hline & \multicolumn{3}{|c|}{ Model 3.1} & \multicolumn{3}{|c|}{ Model 3.2} & \multicolumn{3}{|c|}{ Model 3.3} & \multicolumn{3}{|c|}{ Model 4} \\
\hline & $\mathrm{OR}$ & Std. Err. & $p$ & $\mathrm{OR}$ & Std. Err. & $p$ & $\mathrm{OR}$ & Std. Err. & $p$ & OR & Std. Err. & $p$ \\
\hline Born in the UK & 0.87 & 0.05 & 0.02 & 0.87 & 0.05 & 0.02 & 0.87 & 0.05 & 0.021 & 0.88 & 0.04 & 0.005 \\
\hline Married & 1.13 & 0.06 & 0.025 & 1.12 & 0.06 & 0.029 & 1.12 & 0.06 & 0.026 & 1.14 & 0.05 & 0.001 \\
\hline Main language English & 0.99 & 0.06 & 0.904 & 0.99 & 0.06 & 0.897 & 0.99 & 0.06 & 0.895 & 1.14 & 0.05 & 0.003 \\
\hline Lived for 5 years or longer & 1.22 & 0.06 & $<0.001$ & 1.22 & 0.06 & $<0.001$ & 1.22 & 0.06 & $<0.001$ & 1.16 & 0.05 & $<0.001$ \\
\hline \multicolumn{13}{|c|}{ Socio-economic status (ref: Higher and lower management) } \\
\hline Intermediate; small employers & 0.8 & 0.06 & 0.002 & 0.8 & 0.06 & 0.003 & 0.8 & 0.06 & 0.002 & 0.82 & 0.05 & $<0.001$ \\
\hline Semi-routine and routine & 0.66 & 0.05 & $<0.001$ & 0.66 & 0.05 & $<0.001$ & 0.66 & 0.05 & $<0.001$ & 0.7 & 0.04 & $<0.001$ \\
\hline Other (never work/long-term unem/students) & 0.77 & 0.06 & 0.001 & 0.77 & 0.06 & 0.001 & 0.77 & 0.06 & 0.001 & 0.79 & 0.05 & $<0.001$ \\
\hline Married households with dependent children & 1.01 & 0.01 & 0.241 & 1.01 & 0.01 & 0.398 & 1.01 & 0.01 & 0.234 & 1 & 0.01 & 0.933 \\
\hline Income deprivation score & 0.88 & 0.02 & $<0.001$ & 0.88 & 0.02 & $<0.001$ & 0.89 & 0.02 & $<0.001$ & 0.89 & 0.01 & $<0.001$ \\
\hline Crime deprivation score & 0.96 & 0.02 & 0.072 & 0.96 & 0.02 & 0.041 & 0.96 & 0.02 & 0.062 & 0.96 & 0.02 & 0.016 \\
\hline Percentage of population aged $65+$ & 1.03 & 0.01 & 0.006 & 1.03 & 0.01 & 0.008 & 1.03 & 0.01 & 0.005 & 1.02 & 0.01 & 0.04 \\
\hline Rural & 1.47 & 0.35 & 0.112 & 1.56 & 0.37 & 0.058 & 1.59 & 0.37 & 0.047 & 1.64 & 0.36 & 0.023 \\
\hline Proportion of population in the same ethnic group & 1.09 & 0.28 & 0.738 & 0.7 & 0.33 & 0.439 & 1.1 & 0.28 & 0.721 & 1.2 & 0.24 & 0.362 \\
\hline Proportion of population with the same religion & 1.14 & 0.24 & 0.521 & 1.07 & 0.24 & 0.779 & 1.16 & 0.24 & 0.49 & 1.45 & 0.24 & 0.023 \\
\hline Ethnic Diversity Index & 0.08 & 0.07 & 0.003 & 0.15 & 0.07 & $<0.001$ & 0.44 & 0.45 & 0.42 & 0.19 & 0.08 & $<0.001$ \\
\hline Cannot speak English well (\%) & 0.95 & 0.02 & 0.033 & 0.98 & 0.01 & 0.117 & 1 & 0.06 & 0.976 & 0.98 & 0.01 & 0.176 \\
\hline Ethnic Diversity Index ${ }^{*}$ Cannot speak English well & 1.05 & 0.02 & 0.031 & 1.07 & 0.02 & 0.001 & 0.97 & 0.09 & 0.747 & 1.06 & 0.02 & 0.002 \\
\hline Ethnic Diversity Index $\wedge 2$ & 2.58 & 2.01 & 0.224 & & & & & & & & & \\
\hline Cannot speak English well^2 & 1 & 0.00 & 0.08 & & & & 1.00 & 0.00 & 0.78 & & & \\
\hline \%ethnicity*\%religion & & & & 2.67 & 2.16 & 0.225 & & & & & & \\
\hline Ethnic Diversity Index*Cannot speak English well $\wedge 2$ & & & & & & & 1.00 & 0.00 & 0.341 & & & \\
\hline LA var & 0.1 & 0.03 & & 0.09 & 0.03 & & 0.09 & 0.03 & & 0.08 & 0.02 & \\
\hline MSOA var & 0.27 & 0.04 & & 0.28 & 0.05 & & 0.27 & 0.04 & & 0.23 & 0.03 & \\
\hline $\mathrm{N}$ & df & AIC & $\mathrm{BIC}$ & df & AIC & $\mathrm{BIC}$ & df & $\mathrm{AIC}$ & BIC & df & AIC & $\mathrm{BIC}$ \\
\hline 11,781 & 45 & 12,297 & 12,628 & 44 & 12,297 & 12,622 & 45 & 12,297 & 12,629 & 45 & 27,232 & 27,563 \\
\hline
\end{tabular}

